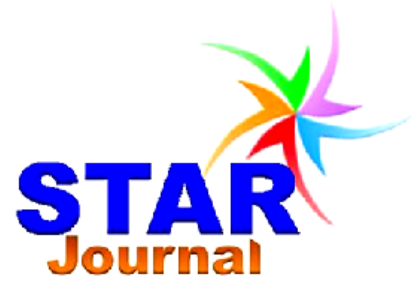

ISSN: 2226-7522(Print) and 2305-3327(Online)
Science, Technology and Arts Research Journal
Oct-Dec 2012, 1(4):84-94
WWW.starjournal.org
Copyright@2012 STAR. All Rights Reserved

Original Research

\title{
Effect of Audio-Visual Intervention Program on Cognitive Development of the Preschool Children
}

\author{
Sushanta Kumar Roul
}

Department of Educational Planning and Management, Bahir Dar University, Bahir Dar, Ethiopia

\begin{tabular}{|c|c|}
\hline Abstract & Article Information \\
\hline Preschool may not be a place where formal education is imparted but yes, it & Received : 12-11-2012 \\
\hline education is the provision of education for children before the commencement of & Revised : 24-12-2012 \\
\hline $\begin{array}{l}\text { statutory education usually between the ages of } 2 \text { and } 5 \text {. Thus the purpose of the } \\
\text { study was to study the effectiveness of the audio-visual intervention program on the }\end{array}$ & Accepted : 27-12-2012 \\
\hline cognitive development of preschool children in relation to their socio economic & Keywords: \\
\hline sample consisted of 100 students from preschool of Rohini, Delhi. Thus the total & Audio-visual, \\
\hline study consisted of 100 children of class L.K.G, besides, all (100) parents of the all & Intervention program \\
\hline sampled children covered under the experimental and control groups were included & Cognitive development \\
\hline Development Test was developed by investigator and Socio Economic Status scale & Preschool children \\
\hline was developed by Rajeev Bhardwaj. The findings of the study were: (i) Audio-visual & ${ }^{*}$ Corresponding \\
\hline of the preschool children; and (ii) the Audio-visual Intervention Program has not & Author: \\
\hline been found to be differently affecting the cognitive development of the preschool & Sushanta Kumar Roul \\
\hline study can be beneficial in strengthening the non-formal preschool education & E-mail: \\
\hline $\begin{array}{l}\text { component. It can be useful for the young children, the teachers who handle the } \\
\text { young children, teacher training institutions and the policy makers as well. }\end{array}$ & drsushantaroul@gmail.com \\
\hline
\end{tabular}

\section{INTRODUCTION}

Education has always been perceived not only as an agent of social change but the basis of creating a dynamic, liberal and growth-oriented society. But if education has to play a significant role in a society it has to assist in the creation of new values and attitudes in the place of the old so that the obstacles in the path of modernization may be removed. For this it is necessary to realize that the foundation of Elementary Education must be firm. Education is important not only for the full development of one's personality, but also for the sustained growth of the nation. Universally, the early childhood years are expected to lay the foundation for inculcation of basic values and social skills in children. It is believed that these values are imbibed from the family. Consequently, in the past, much of the early care and education of the child was informal, within the family and largely through grandmother's caring practices, stories, and traditional infant games, handed down from one generation to the next. This wealth of developmentally appropriate childcare practices is gradually becoming extinct in view of more modern provisions for children and changing social realities.

With growing urbanization, and an increase in women's participation in the work force across the country, among all socio-economic groups, there has been a sea change in the social structure and practices in the last few decades. Elementary Education in India therefore is the foundation on which the development of every citizen and the nation as a whole hinges. But making Elementary Education available for all in India has also been one of the major challenges for the government. Elementary Education in 
Sushanta Kumar Roul

India means eight years of schooling from the age of 6 .

\section{Concept of Pre-School}

Preschool is an educational institution for children. These are also known as Day Care Centres (DCC); Child Care Centres (CCC); Nursery Schools; Kindergarten Schools; Preschools; and Pre-primary Schools. There is no uniformity in the name, content, or scope. In India, early childhood is defined as the period of a child's life from conception to eight years. It includes early stimulation programmes through crèches/home stimulation for 0-3 year olds, Preschool/Early Childhood Education Program (ECEP) for 3-6 year olds, and Early Primary Education Programs as part of primary schooling for 6-8 year olds.

Pre-school may not be a place where formal education is imparted but yes, it definitely is a place where children have their first taste of independence. And today, with both the parents working, pre-school is becoming an inevitable part of a child's life. When we talk about independence, it relates to a child remaining away from his parents for a couple of hours, thus breaking free off the separation anxiety.

At play schools, children are exposed to a lot of basic preschool learning activities that help them to get independent faster. These preschool activities help develop in children many self-help qualities like eating food themselves, dressing up, maintaining cleanliness and other such basic qualities. Development in the early years of life is at its most rapid pace and any kind of environmental enrichment or deprivation is likely to render maximum impact on the organism during this period of most active growth. Preschool education is the provision of education for children before the commencement of statutory education usually between the ages of 2 and 5 .

In pre-primary education importance is not to be given to any kind of formal teaching and learning, attention is to be given to the psychological development of the children. The activities of preschool are to be designed as per the interest and need of the children. So it is ideal not to have a permanent syllabus for the preschool program. Generally, the main activities of pre-schools are: Free-play, Organized play, Story sessions, Music and dance, Acting, Drawing and painting, Creative work, Nature study, Language development, and Including a sense of counting, measurements and weights.
Sci. Technol. Arts Res. J., Oct-Dec 2012, 1(4):84-94

It is in this context that early childhood education is envisaged as a significant intervention to compensate for early environmental deprivation by providing enriching and stimulating experiences to the child which would help to reverse any adverse impact on development. In Indian context, Early Childhood Education has a dual significance: Firstly, it has a direct influence on the holistic development of the child; and secondly, it has the potential to contribute to the programme for universalization of Elementary Education which at present is an outstanding educational priority.

Preschool Education, therefore, becomes for the child, an important aspect to preparation for primary school. This is expected to reduce possibilities of wastage and stagnation in early primary grade. But in our country an organized education of the child below primary school age has not received the desired attention.

\section{Objectives of Pre-School Education}

As the name itself suggests, the prime function of pre-school is of course, to prepare the child for the next stage. This goal could easily be achieved if the needs of the particular stage are met properly. Children between 3 to 5 years of age are actually not matured and ready for the formal instruction in reading, writing and arithmetic. Initiating them into the formal education at this stage may lead to improper development of children by providing the suitable and conducive atmosphere and satisfy their basic needs. The education commission in its report of 1964-66 has pointed out the following as the objectives of preschool education in India:

- To develop in the child good health habits and to build up basic skills necessary for personal adjustment such as dressing, toileting habits, eating, washing, cleaning etc.

- To develop desirable social attitudes and manners to encourage healthy group participation, making the child sensitive to the rights and privileges of others.

- To develop emotional maturity by guiding the child to express, understand, accept and control its feelings and emotions.

- To encourage aesthetic appreciation.

- To encourage independence and creativity by providing the child with sufficient opportunities for self-expressions.

- To develop the child's ability to express its thoughts and feelings in fluent, correct and clear speech.

- To develop in the child a good physique, adequate muscle coordination and basic motor skills. 
Sushanta Kumar Roul

\section{Methods of Preschool Education}

Some schools have adopted specialized methods of teaching such as Montessori, Waldron, Head Start, High Reach Learning, High Scope, the Creative Curriculum, Regale Emil Approach, Book Street and various other pedagogies which contribute to the foundation of education. In spite of all these, in our country an organized education of the child below primary school age did not receive the attention it deserved, until very recently.

\section{Importance of Audio-Visual Aids for Young Children}

There is better understanding today than ever before as to how children learn and what kind of activities and things serve as efficient means and tools of learning. Research has shown that Audio-Visual materials in the form of pictures, charts, maps, slides, film-strips, recordings when properly used can make a significant contribution to learning, reinforcing the role of textbooks, oral instructions and exercises.

The first few years of a child's life are the most impressionable years and the learning experiences provided during these years in or outside the schools and other institutional arrangements have a predominant influence on the future behavioral pattern of the child. Seeing, hearing, touching, smelling and manipulating things in the environment tell the child what the world is like. Sensory experiences of all kinds contribute to strengthen and enrich the child's perception. Toys, building blocks, card-games, puzzles as well as Audio-Visual aids such as pictures, charts, maps, globes, diagrams, flannel graphs, sound-recordings which are basically materials of sight and sound, offer a variety of experiences which stimulate the senses and promote self-activity in children. Audio-Visual aids reinforce the spoken or the written words with concrete images and thus provide rich perceptual experiences which are the basis of learning.

The purpose of education at the preschool level is not so much a question of giving information to children to be memorized as of deeply stimulating their senses, arousing their curiosity, stimulating inquiry and helping them to achieve significant perceptual growth. If these are objectives of education, then the learning environment has to be suitably designed. Designing the environment means to create maximum opportunities for children to observe and work with several things which contribute to their understanding of man and the world. Looking at the pictures, listening to a story,
Sci. Technol. Arts Res. J., Oct-Dec 2012, 1(4):84-94

listening to recordings of speeches of great birds and animals, playing with educational toys, working with building blocks, stringing beads, sorting color blocks and shapes, matching them to pieces of colored fabric, touching pet animals, looking at a puppet-show are some of the interesting activities which provide concrete learning experiences to children and help them to develop new attitudes towards learning. Consequently, the role of the teacher of today has changed from a transmitter of information to that of a planner and organizer of appropriate learning experiences with the management of a variety of teaching and learning materials with a view to creating a stimulating environment for learning.

Conveying ideas skillfully to children is another important task for the teacher of preschool and primary school children. Audio-Visual aids in various forms are of immerse help to the teacher in this task. A picture or a chart or even a simple drawing on the blackboard can provide the child an entirely new experience in understanding an idea or a concept than more words. Words have different meanings to different individuals but a picture or a drawing can to a much greater extent convey what we have in our mind. Ideas that often seem quite simple to us may not be so simple and clear to the child. But if the child could 'see' what we are talking about, it helps it to understand what we exactly mean in our words: 'seeing believes'.

A visual presentation of an idea or a concept using a picture or a chart or a model helps children to develop mental images of the object that we are talking about. A mere verbal presentation or a lecture cannot serve this purpose. A visual presentation adds variety to teaching and breaks the monotony in the classroom instruction. An old proverb says: If I hear, I forget; If I see, I remember; and If I do, I understand.

Seeing and hearing together can be more convincing and effective than just hearing. The child gets bored with the pictures but love to look at pictures of different kinds presented before him. Today the child in the preschool is required to learn increasingly complex information and skills in a highly complicated world. Research shows that $80 \%$ of learning occurs through the sense of sight and hearing and, therefore, planned use of audio-visual aids which are essentially materials of sight and sound, help to improve learning and teaching. This important principle is the basis of audio-visual aids to education. 


\section{Sushanta Kumar Roul}

Sound and image play such an important role in the learning process that a large number of sound and visual devices have been produced as a result of development of technology in relation to education. These educational devices are a source of great help to teachers to provide exciting learning experiences to children. Foremost among them is the tape-recorder and audio CDs for language teaching. It provides immediate facilities for recording the speech as soon and as often as may be required. Such modern aids provide the possibility of a much fuller and wider visual presentation of objects and events that a teacher could ever produce previously. Slides, filmstrips, and other aids can bring into the class-room a representation of virtually all objects, situations and actions of normal life. The presentation can also be controlled and graded, so that there is systematic progression from one point to the other.

Anandlakshmy (1990) conducted a play intervention study which investigated the role of several variables in the development of cognition during childhood. The two components which she found were: the intervention group improved cognitive behavior (attention span, goal directedness, creativity) and sensory areas interest. It emerged that on the convergent problems play experiences were as useful as the comparable non-play experiences but not remarkably superior. On the divergent tasks the superiority of the play groups was evident. Mohanty (1990) conducted a study on critical appraisal of primary school audio programs and their effectiveness for pupil growth. The study revealed that the comprehension of audio programs by students was moderate and not satisfactory. Programs that had features, drama, story formats were comparatively better comprehend, rural children as compared to urban children gained significantly less. Kothari and Chowdhary (1995) studied the impact of television programs on behavior of students of different age levels, and they found that girls had more positive effect on their emotional and cognitive behavior than boys. As regard the impact of television programs on moral behavior negative effect was more than the positive one. Sahoo (1995, cited in Indian Educational Abstract, 1996) recorded that radio intervention program has positive effect on student learning. However, no gender difference was found in learning of students. Kaswakar (1996) undertook for her Ph.D. work construction and effectiveness of multimedia package to develop population awareness. She found that it was significantly effective in comparison to actual method and develop awareness to a significant degree.
Sci. Technol. Arts Res. J., Oct-Dec 2012, 1(4):84-94

Multimedia package was more effective in changing the attitude of teacher trainees. Bhangoo and Sidhu (1997) studied the impact of selected audio-visual aids on food hygiene knowledge of secondary school students. They found that students taught with audio-visual materials performed better than the controlled group.

Marthanda (1998) in his PhD study found that Audio-tapes were found more effective in retention as well as in changing attitude as compared to lecture method. Neera (1996) took a study to compare effectiveness of video teaching learning material (VTLM), video aided instruction (VAI) and conventional teaching. He found students most favorably disposed towards VTLM. Retention with VTLM and Vai was more effective than CT. Students retained more who were exposed to VTLM than students who were exposed to VAI. Students exposed to VTLM and VAl were significantly different in their achievements. Glass (1999) took up a study on the need of cognitive stimulation and supportive environments to support a series of developmental steps in early infancy and found that the absence of such environments can lead to later cognitive impairment. Although early childhood provides foundations for later development, middle childhood also provides education and social experience that are critical for developmental outcomes. Saha (2005) conducted a study on the Influence of School Environment on Cognitive Development of Children with the objective to study the influence of school environment on cognitive development of students and found that the school environment exerted positive influence on cognitive development of children. Arora, et al. (2006) conducted the study on Evaluation of Nonformal Pre-school Services provided by Anganwadi Centers (Urban Slums of Jammu City). They found that the non-formal pre-school education was provided to children at centers and workers used two way interaction methods and takes the help of teaching aids for imparting education to the children. Indigenous material was used to make teaching aids like puppets, vegetables and fruits and most of parents were satisfied with non-formal education provided at Anganwadi centers but few weren't, as they felt that Anganwadi workers laid more emphasis on nutrition and health. Meenu (2006) studied the Utilization and Effectiveness of Educational Television Programs at Primary School Level. The main Findings were: (i) The ETV lessons in Mathematics and EVS taught to students of both Class III and V significantly improved their learning achievement as compared to their 
Sushanta Kumar Roul

counterparts taught through traditional method. (ii) The experiment also showed that ETV lessons developed more favorable teacher attitude and learner reactions towards ETV programs. The improvement in learning achievement has played an important role in developing positive social scale values.

\section{Need and Significance of the Study}

The foregoing discussion makes it clear that since 1950 determined efforts have been made towards the achievement of Universalization of Elementary Education (UEE). Over the years there has been a very impressive expansion in the provision of educational facilities and enrolment. However, the goal of UEE which was envisaged in the constitution of India to be achieved by 1960 is still an elusive goal and much ground is yet to be covered. Also the dropout rates continue to be significant, retention of children in schools is low and wastage considerable. Dropout rate is much higher among girls and weaker sections of the society.

Despite all the financial constraints aggravated by population explosion, poverty and illiteracy of the masses; large rural habitation; wide gulf between the availability and accessibility; inequality in opportunity owing largely to socioeconomic disparities and more significantly in the context of remote, desert, hilly and tribal areas and failure to provide adequate work ethics are among the major stumbling blocks in making the elementary education free and compulsory. Also, it is a well known fact that the primary education forms the foundation for further education. In order to make primary education broad based and stronger than before, there is a need to strengthen the pre-school education component. It provides children with stimulating experience for cognitive, language, physical, social and emotional development. It prepares a child with the necessary concepts, for the later learning of reading, writing and mathematics in primary grades.

Simultaneously, it provides a school-readiness program to the child i.e. it prepares him/her with the necessary concepts, language and physical skills for the later learning of reading, writing and mathematics in primary grades. It helps the child to develop other competencies too i.e. getting along with other children, following a routine programme, learning to sit and concentrate on an activity for a period of time, widening of the attention span etc. All these skills and competencies help in adjustment in the first few years of primary school. Also these children will make better progress in primary education. A
Sci. Technol. Arts Res. J., Oct-Dec 2012, 1(4):84-94

study conducted by Kaul (1993) is evidence that the children exposed to preschool education were found to be superior in every aspect in comparison to the children who were not exposed. Early Childhood Education to some extent also leads to reduction in the number of dropouts and failures at the primary level and also has a positive impact on the enrolment of girls, which has been a serious concern for the last few decades. If organized effectively, an ECE programme can compensate for the deprivation at home front and can help the child build a strong foundation which would later facilitate the development of his full potential.

Recently, there has been an emphasis on the use of educational technology in facilitating learning at various levels of education. The use of educational technology even at preschool level seems to be promising in making learning both effective and interesting. In fact, at this stage it seems to be more relevant as young children may find it most natural and enjoyable. In this context some mass media technology like TV and Radio are perceived as of possible help to children to their development in a more natural manner. Such an approach can also be made use of in the preschool activities organized in the preschools. Increasingly the effectiveness of such centers constitutes a huge structure and given due emphasis by the government. Some initial efforts have been made by N.C.E.R.T., New Delhi by designing some programs for radio broadcast in collaboration of All India Radio. But the effectiveness of such programs is more often believed than investigated. Therefore, there is a need to conduct some impact studies on the effectiveness of such programs.

\section{Objectives}

- To study the effectiveness of the Audio-visual Intervention Program on the cognitive development of preschool children.

- To study the difference between the Mean Pre-Test and Post-Test scores of Experimental Group on Cognitive Development with effects of audio-visual intervention program of preschool children.

- To study the difference between the Mean Pre-Test and Post-Test scores of Control Group on Cognitive Development with effects of any intervening variable of preschool children.

- To study the effectiveness of the Audio-visual Intervention Program on the cognitive development of preschool children in relation to their socioeconomic status. 
Sushanta Kumar Roul

\section{MATERIALS AND METHODS}

Keeping in mind the nature and need of the present research, the Experimental Method was considered to be the appropriate one. Experimentation is the classical method of the science laboratory, where elements manipulated and effects observed can be controlled. It can be effectively applied within non-laboratory settings such as the classroom, where significant factors or variables can be controlled to some degree. In educational research, experimental method is the application and adoption of the classical method of science laboratory.

\section{Sample}

The sample consisted of 100 students from preschool of Rohini, Delhi. The cluster random sampling technique was used to select one preschool out of total preschools in Rohini, Delhi. From that particular school, all (2 sections $\times 50$ students) 100 children of class Lower K.G. were included as the sample of the study to constitute the experimental and control groups. Thus the total study consisted of 100 children of class L.K.G., in addition, all (100) parents of the all sampled children covered under the experimental and control groups were included in the sample so as to collect the data related to their socioeconomic status.

\section{Tools Used}

\section{Cognitive Development Test:}

To study the effectiveness of the Audio-visual Intervention Program on the Cognitive development of the preschool children, the Cognitive Development Test was developed by investigator. The cognitive development of the preschool children was measured in terms of their awareness of immediate environment, awareness of cultural heritage, concept of color and shape.

a.Awareness of Immediate Environment: This sub-test has a set of flash cards depicting the child's immediate surroundings. The themes are on plants and animals (wild animals, pet animals and water animals), Fruits and Means of Transport. Specific questions pertaining to each card are asked.

b. Awareness of Cultural Heritage: A set of flash cards prepared to test the child's awareness of his/her cultural heritage. Cards on Mahatma Gandhi, National Flag, National Animal, National Bird and Diwali festival are included in the same. Questions are asked on each card moving from simple to complex.

c. Concept of Color and Shape: In this sub-test the wooden blocks of Red, Yellow and Blue
Sci. Technol. Arts Res. J., Oct-Dec 2012, 1(4):84-94

colors are used to measure the concept of color. Also wooden blocks of Circle, Triangle, Rectangle and Square are used to measure the concept of shape. The blocks are kept in front of child and questions are asked regarding the colors and shapes of theses blocks.

d. Sequential Thinking: A set of four flash cards depicting sequential steps in bathing is presented to the child in a proper sequence and related questions are asked. Later on the cards are mixed and placed in front of the child, and then each child is asked to arrange the cards in a sequence. Marks are given for arranging the cards in a proper sequence.

\section{Socio Economic Status Scale (SES)}

The investigator also used the Socio Economic Status standardized scale developed by Rajeev Bhardwaj. This scale has been devised to measure the socio economic status of parents of students. The reliability and validity of the said test were found to maximum.

\section{Procedure of Data Collection}

For actually conducting the experiment, the preschool teacher was given a two day orientation and training as to how the study is to be conducted with clear perception of the roles. On the first day, importance of the use of audiovisual aids in imparting education to preschool children is given. The sessions were supplemented with number of selected audio programmes and demonstration by using simulation and micro-teaching strategies. On the second day the same activity is demonstrated. Since the subjects of the present study were preschool children it was not possible to collect data regarding their SES from the children themselves. Therefore, the data regarding their SES was collected from their parents. This data formed the basis for assigning the subjects to the experimental and control group. In order to ensure the homogeneity among the experimental and control groups, pre-testing was done on cognitive development tests. This was the main base to ensure that the experimental and control groups are equal and matched with respect to the variables under investigation before the commencement of the experiment.

\section{Statistical Techniques}

After the treatment and the post-test, the performance of the experimental and control groups were to be compared on cognitive development. The statistical techniques of Mean, Standard deviation and't'-test techniques were employed to see the difference between experimental and control group of experiment. 


\section{RESULTS AND DISCUSSION}

The difference in the mean post-test scores of experimental and control group on cognitive development of preschool children is provided below in Table 1.

Table 1: Significance of Difference between the Mean Post-Test Scores of Experimental and Control Groups Cognitive Development.

\begin{tabular}{lccccc}
\hline \multicolumn{1}{c}{ Contents } & Groups & $\mathbf{n}$ & Mean & SD & t-ratio \\
\hline \multirow{2}{*}{ Environmental Awareness (EA) } & Experimental & 50 & 77.86 & 4.72 & \multirow{2}{*}{$39.30^{* *}$} \\
& Control & 50 & 38.32 & 5.60 & \\
\hline \multirow{2}{*}{ Cultural Heritage $(\mathrm{CH})$} & Experimental & 50 & 32.66 & 3.04 & \multirow{2}{*}{$27.63^{* *}$} \\
\hline \multirow{2}{*}{ Concept of Color and Shape } & Control & 50 & 12.78 & 4.02 & \\
& Experimental & 50 & 12.58 & 2.51 & \multirow{2}{*}{$9.04^{* *}$} \\
\hline \multirow{2}{*}{ Sequential Thinking (ST) } & Control & 50 & 8.56 & 1.96 & \\
& Experimental & 50 & 8.00 & 0 & \multirow{2}{*}{$15.65^{* *}$} \\
\hline \multirow{2}{*}{ Cognitive Development Total } & Control & 50 & 4.00 & 1.79 & \\
& Experimental & 50 & 131.26 & 7.58 & \multirow{2}{*}{$41.51^{* *}$} \\
\hline
\end{tabular}

*at 0.05 level: 1.96

**at 0.01 level: 2.58

The mean post-test scores of experimental group on environmental awareness, cultural heritage, concept of color and shape, sequential thinking and cognitive development total are found to be 77.86, 32.66, 12.58, 8.00 and 131.26 respectively with S.D. s' $4.72,3.04,2.51,0$ and 7.58. Similarly, the mean post-test scores of control group on environmental awareness, cultural heritage, concept of color and shape, sequential thinking and cognitive development total are found to be $38.32,12.78,8.56,4.00$ and 63.30 respectively with S.D. s' $5.60,4.02,1.96$, 1.79 and 8.59. The t-ratio between the two groups comes out to be $39.30,27.63,9.04,15.65$ and 41.51. It is significant beyond at .01 level as well as at 0.05 level of significance. It indicates that the pre-school children of the two groups differ significantly in cognitive development in general.

The comparison of mean scores further reveals that the mean score of experimental group is much higher than the control group. It means that the audio-visual intervention program is found to have a positive effect on the cognitive development of preschool children. Thus the Hypothesis (H1) that "the audio-visual intervention program will have a positive effect on the cognitive development of the preschool children" is retained. From the results of the preceding phase, it is evident that the calculated $t$-values of cognitive development of post-test experimental group are significant at a very higher level. The results revealed that the preschool children, who were exposed to the audio-visual intervention program performed better than those who were not exposed.

The comparison between the pre-test and post-test mean scores of experimental group (Table 2) would be made in this section to determine whether or not certain kind of Audiovisual Intervention Program effects cognitive development of preschool children.

Table 2: Significance of difference between the Mean Pre-test and Post-test scores of Experimental Group on Cognitive Development.

\begin{tabular}{cccccc}
\hline Contents & Groups & N & Mean & SD & t-ratio \\
\hline \multirow{2}{*}{ Cognitive Development Total } & Pre-test & 50 & 62.03 & 14.34 & \multirow{2}{*}{$29.76{ }^{* *}$} \\
\cline { 2 - 5 } & Post-test & 50 & 131.26 & 7.58 & \\
\hline
\end{tabular}

*at 0.05 level: 1.96

**at 0.01 level: 2.58 


\section{Sushanta Kumar Roul}

It can be seen that the mean pre-test and post test scores of experimental group on cognitive development total is found to be 62.03 and 131.26 respectively with S.D. s' 14.34 and 7.58 . The t-ratio between the two groups comes out to be 29.76. It is significant at 0.01 level of significance. It indicates that the pre-school children of the two groups differ significantly in their cognitive development total scores.

The comparison of mean scores further reveals that the mean score of experimental
Sci. Technol. Arts Res. J., Oct-Dec 2012, 1(4):84-94

group in post-test is much higher than the pretest. It means that the audio-visual intervention program is found to have a positive effect on the cognitive development total of preschool children.

The comparison between the pre-test and post-test mean scores of control group (Table 3 ) would be made in this section to determine whether or not some intervening variables have affected the cognitive development of preschool children during the audio-visual intervention program.

Table 3: Significance of difference between the Mean Pre-test and Post-test scores of Control Group on Language Development.

\begin{tabular}{cccccc}
\hline Contents & Groups & N & Mean & SD & t-ratio \\
\hline \multirow{2}{*}{ Cognitive Development Total } & Pre-test & 50 & 62.02 & 11.68 & \multirow{2}{*}{0.61} \\
\cline { 2 - 5 } & Post-test & 50 & 63.30 & 8.59 & \\
\hline
\end{tabular}

*at 0.05 level: 1.96
**at 0.01 level: 2.58

It can be seen that the mean pre-test and post-test scores of control group on cognitive development total are found to be 62.02 and 63.30 respectively with S.D.s' 11.68 and 8.59 . The t-ratio between the two groups comes out to be 0.61 . It is less than the table value at df of 98 and not significant even at 0.05 level of significance. It indicates that in the present study, the pre-test and post-test scores of control group are not found to differ on the cognitive development scores. It means that in the present study no intervening variable is affecting on the cognitive development of preschool children.

From the results of the preceding phase, it is evident that the calculated t-values of cognitive development total of pre-test and post-test experimental group are significant at a very higher level. The results revealed that the preschool children, who were exposed to the audio-visual intervention program performed better than those who were not.

The effectiveness of the Audio-visual Intervention Program on the Cognitive Development of Preschool children in relation to their socio-economic status is presented below in Table 4.

Between High and Low Socio Economic Status: The result reveals that the mean posttest scores of the children of high SES experimental group on awareness of immediate environment, awareness of cultural heritage, concept of color and shape, sequential thinking and cognitive development total are found to be
$78.71,33.21,12.71,8.00$ and 132.93 respectively with their S.D's 11.63, 1.52, 2.68, 0 and 6.72 . Similarly the mean post-test scores of low SES children of the experimental group on the four dimensions and cognitive development total are found to be $76.1,31.8,12.8,8.00$ and 128.7 respectively with their S.D's $5.01,4.42,2.56,0$ and 8.66. The t-ratio between the two groups on cognitive development and its four dimensions come out to be 1.30, 1.46, 1.06, 0.08 and 0 respectively. None of the t-ratio is significant even at 0.05 level. It shows that the children of high and low SES exposed to the audio-visual intervention program do not differ significantly on cognitive development and its four dimensions.

It can be interpreted to mean that in the present study Audio-visual Intervention Program has not been found to be differentially affecting the cognitive development pre-school children at different SES level.

Between High and Middle Socio Economic Status: The result reveals that the mean posttest scores of the children of high SES experimental group on awareness of immediate environment, awareness of cultural heritage, concept of color and shape, sequential thinking and cognitive development total are found to be $78.71,33.21,12.71,8.00$ and 132.93 respectively with their S.D's $3.41,1.32,2.68,0$ and 6.72 . Similarly the mean post-test scores of middle SES children of the experimental group on the four dimensions and cognitive development total are found to be $78.08,32.69,12.58,8.00$ and 131.35 respectively with their S.D's $4.19,2.92$, 


\section{Sushanta Kumar Roul}

2.36, 0 and 7.30. The t-ratio between the two groups on cognitive development and its four dimensions come out to be $0.27,0.47,0.62,0.15$ and 0 respectively. None of the t-ratio is significant even at 0.05 level. It shows that the children of high and middle SES exposed to the Audio-visual Intervention Program do not differ
Sci. Technol. Arts Res. J., Oct-Dec 2012, 1(4):84-94

significantly on cognitive development and its four dimensions.

It can be interpreted to mean that in the present study Audio-visual Intervention Program has not been found to be differentially affecting the cognitive development pre-school children at different SES level.

Table 4: Significance between the mean post-test experimental group scores in cognitive development of pre-school children with different levels of SES.

\begin{tabular}{|c|c|c|c|c|}
\hline Contents & Groups & Mean & SD & t-ratio \\
\hline \multirow{2}{*}{ Environmental Awareness } & High & 78.71 & 11.63 & \multirow[b]{2}{*}{1.46} \\
\hline & Low & 76.1 & 5.01 & \\
\hline \multirow{2}{*}{ Cultural Heritage } & High & 33.21 & 1.52 & \multirow[b]{2}{*}{1.06} \\
\hline & Low & 31.8 & 4.42 & \\
\hline \multirow{2}{*}{ Color and Shape } & High & 12.71 & 2.68 & \multirow[b]{2}{*}{0.08} \\
\hline & Low & 12.8 & 2.56 & \\
\hline \multirow{2}{*}{ Sequential Thinking } & High & 8.00 & 0 & \multirow[b]{2}{*}{0} \\
\hline & Low & 8.00 & 0 & \\
\hline \multirow{2}{*}{ Cognitive Development Total } & High & 132.93 & 6.72 & \multirow{2}{*}{1.30} \\
\hline & Low & 128.7 & 8.66 & \\
\hline \multirow{2}{*}{ Environmental awareness } & High & 78.71 & 11.63 & \multirow[b]{2}{*}{0.47} \\
\hline & Middle & 78.08 & 4.19 & \\
\hline \multirow{2}{*}{ Cultural heritage } & High & 33.21 & 1.52 & \multirow[b]{2}{*}{0.62} \\
\hline & Middle & 32.69 & 2.92 & \\
\hline \multirow{2}{*}{ Color and shape } & High & 12.71 & 2.68 & \multirow[b]{2}{*}{0.15} \\
\hline & Middle & 12.58 & 2.36 & \\
\hline \multirow{2}{*}{ Sequential Thinking } & High & 8.00 & 0 & \multirow[b]{2}{*}{0} \\
\hline & Middle & 8.00 & 0 & \\
\hline \multirow{2}{*}{ Cognitive Development Total } & High & 132.93 & 6.72 & \multirow{2}{*}{1.27} \\
\hline & Middle & 131.35 & 7.30 & \\
\hline \multirow{2}{*}{ Environmental Awareness } & Middle & 78.08 & 4.19 & \multirow{2}{*}{1.03} \\
\hline & Low & 76.1 & 5.01 & \\
\hline \multirow{2}{*}{ Cultural Heritage } & Middle & 33.69 & 2.92 & \multirow[t]{2}{*}{0.68} \\
\hline & Low & 31.8 & 4.42 & \\
\hline \multirow{2}{*}{ Color and Shape } & Middle & 12.58 & 2.36 & \multirow[t]{2}{*}{0.54} \\
\hline & Low & 12.8 & 2.56 & \\
\hline \multirow{2}{*}{ Sequential Thinking } & Middle & 8.00 & 0 & \multirow{2}{*}{0} \\
\hline & Low & 8.00 & 0 & \\
\hline \multirow{2}{*}{ Cognitive Development Total } & Middle & 131.35 & 7.30 & \multirow{2}{*}{0.76} \\
\hline & Low & 128.7 & 8.66 & \\
\hline
\end{tabular}

*at .05 level: 1.96

**at .01 level: 2.58 


\section{Sushanta Kumar Roul}

Between Middle and Low Socio Economic Status: The result reveals that the mean posttest scores of the children of middle SES experimental group on awareness of immediate environment, awareness of cultural heritage, concept of color and shape, sequential thinking and cognitive development total are found to be $78.08,32.69,12.58,8.00$ and 131.35 respectively with their S.D's 4.19, 2.92, 2.36, 0 and 7.30. Similarly the mean post-test scores of low SES children of the experimental group on the four dimensions and cognitive development total are found to be $76.1,31.8,12.8,8.00$ and 128.7 respectively with their S.D's $5.01,4.42,2.56,0$ and 8.66. The t-ratio between the two groups on cognitive development and its four dimensions come out to be $0.76,1.03,0.68,0.54$ and 0 respectively. None of the t-ratio is significant even at 0.05 level. It shows that the children of high and middle SES exposed to the Audio-visual Intervention Program do not differ significantly on cognitive development and its four dimensions.

It can be interpreted to mean that in the present study Audio-visual Intervention Program has not been found to be differentially affecting the cognitive development pre-school children at different SES level. Thus the Hypothesis that "The Audio-visual Intervention Program on the Cognitive Development of pre-school children will differ significantly at different SES level" is rejected.

\section{Findings}

1. The Audio-visual Intervention Program has a positive effect on the awareness of the immediate environment of the pre-school children.

2. The Audio-visual Intervention Program has a positive effect on the awareness of the cultural heritage of the pre-school children.

3. The Audio-visual Intervention Program has a positive effect on the development of concept of color and shape among pre-school children.

4. The Audio-visual Intervention Program has a positive effect on the sequential thinking of the pre-school children.

5. The Audio-visual Intervention Program has also positively affected the overall cognitive development of the pre-school children.

6. The Audio-visual Intervention Program has not been found to be differently affecting the cognitive development of the pre-school boys and girls.

7. The Audio-visual Intervention Program has not been found to be differently affecting the cognitive development of the pre-school children at different SES levels.
Sci. Technol. Arts Res. J., Oct-Dec 2012, 1(4):84-94

Based on the findings, it is evident that audiovisual intervention programme is capable of providing valuable assistance to the pre-school teachers in the non-formal pre-school setting by presenting worthwhile information and learning experiences simultaneously to a large number of students. Hence, in many ways the findings of the present study can be beneficial in strengthening the non-formal pre-school education component. The finding can be useful for the young children, the teachers who handle the young children, teacher training institutions and the policy makers as well.

In the absence of a structured and prescribed syllabus for the non-formal pre-school education component such programmes for conducting the non-formal pre-school activities in the preschools. Even the daily three hours non-formal pre-school activities can be based on the specific themes of the audio-visual programme. By which the same theme can be recapitulated/repeated in one way or the other. In the absence of a well sequenced material and printed text-books, the content of the programme can be printed along with the activities and supplied as guide books to the teachers, so that the teachers can prepare themselves to conduct activities.

It has already been discussed earlier that each programme is in a magazine format and of 15 minutes duration keeping in view the pedagogical considerations each program includes conversation, song, story, drama, riddles, music and sound effects and fun and humor in it. Hence the programme can arouse interest, increase attention span and develop language among the young children. The present study therefore, strengthens the use of all such activities in organizing the pre-school education. Therefore, such programmes should be a regular feature in pre-schools so as to help enhance the language development process of the young children and strengthen the ability of the teachers by providing worthwhile information, which are useful in our daily life.

\section{CONCLUSION}

As the content of the Audio-visual programme are researched well before its presentation so the teachers can get authentic information which is useful for them as well as for the young children they handle. Also the findings of this study can be equally useful for the other functionaries i.e. programme officers, child development project officers, supervisors and the teacher educators of the pre-school teacher training institute who can always train the pre-school teachers, keeping in 


\section{Sushanta Kumar Roul}

view, the mental, physical, social and psychological need of the young child. Also there is a need to train the pre-school teachers about the process of conducting activities either in the pre-service or in-service training. The findings of the present study can also be beneficial for the policy makers who in turn may try to strengthen the pre-school education component by allocating additional funds and planning more such programs in future.

\section{REFERENCE}

Arora, S., Bharati, S. \& Mahajan, A. (2006). Evaluation of Non-formal Pre-school Services provided Anganwadi Centers (Urban Slums of Jammu City). Journal of Social Science 12(2):135-37.

Anandlakshmy, S. (1998). The cultural context. In: Swaminathan, M. (Ed.). The first five years: a critical perspective on early childhood care and education in India. New Delhi: Sage.

Bhangoo, S. (1997). Impact of selected audio-visual aids on food hygiene knowledge of school students. Trends in Education xxxii (1).

Bharadwaj R.L. (1980). Socio-economic Status Scale. Agra: National Psychological Corporation.

Glass, N. (1999). Sure Start: The Development of an early intervention programme for young Children in the United Kingdom. Children and Society 13:257264.

Government of India (1986). National Policy on Education. MHRD (Department of Education), New Delhi.

Kaul, V. (1993). Pre-school curriculum recommended by the National Council for Educational Research and Training. Calcutta: National Conference on Pre-school Stress.

Kaswakar, P.A. (1996). Construction and effectiveness of multimedia package to develop population awareness in the trainees of primary teacher
Sci. Technol. Arts Res. J., Oct-Dec 2012, 1(4):84-94

training institutions. Unpublished thesis of Ph.D., Gujarat Vidyapith. Gujarat.

Kothari, S. and Choudhary, M. (1995). Impact of television program on behavior of students of various age levels. Psycho-Lingua 25(1/2): 43-50

Marthanda, V. K. (1998). Effectiveness of instructional media in modifying cognitive and affective behavior in prevention and control of Acquired Immune Deficiency Syndrome (AIDS). Unpublished thesis of Ph.D., Utkal University, Orissa.

Meenu (2006). Utilization and Effectiveness of Educational Television Programs at Primary School Level. Indian Educational Review 41(1): 79-89.

Ministry of Home Affairs (2011). Census Report of India. New Delhi: Government of India.

Ministry of Human Resource Development (1994). District Primary Education Program (DPEP). New Delhi: Department of Education, Govt. of India.

Ministry of Human Resource Development (2001). Sarva Shiksha Abhiyan: Program for Universalization of Elementary Education in India. New Delhi: Department of Elementary Education and Literacy, Government of India.

Mohanty, M.K. (1990). A Critical Appraisal of Primary School Radio Programmes and Their Effectiveness for Pupils' Growth. Ph.D. thesis, Utkal University, Bhubaneswar.

N.C.E.R.T. (1996). Indian Educational Abstracts. New Delhi.

Neera, C. L. (1996). The production and validation of video teaching-learning material in home science for senior secondary students of Delhi. Unpublished thesis of Ph.D., University of Jamia Millia Islamia, New Delhi.

Saha, K. (2005). The Influence of School Environment on Cognitive Development of Children: A Study. Journal of All India Association for Educational Research 17(1-2): 58-59. 